\title{
22. DATA REPORT: AMINO ACID RACEMIZATION GEOCHRONOLOGICAL STUDIES OF SELECTED LEG 155 SAMPLES ${ }^{1}$
}

\author{
John F. Wehmiller ${ }^{2}$ and Frank R. Hall ${ }^{3}$
}

\begin{abstract}
Amino acid racemization measurements have been conducted on selected samples from Ocean Drilling Program (ODP) Leg 155 to evaluate the utility of this method for geochronological purposes. Sample size limited the number of analyses, but samples that were successfully processed included one sample of Holocene age, one from oxygen isotope Substage 5e, and two pre-Substage 5e samples. These latter two samples appear to be Stage 7 age, possibly Stage 9 . One is from a disturbed zone that could include specimens of different ages. Geothermal heating effects on racemization are potentially significant for these samples and require further evaluation.
\end{abstract}

\section{INTRODUCTION}

The sediments of the Amazon Fan consist mostly of terrigenous particles originating from the South American continent, delivered primarily as turbidites and other forms of mass wasting such as debris flows (Flood, Piper, Klaus, et al., 1995). The high terrigenous inputs into these locations, primarily during glacial periods, commonly result in low populations of microfossils within sedimentary units. In contrast, during interglacial periods, microfossil numbers can increase significantly as the continental shelf is drowned, cutting off the source of terrigenous particles.

Understanding the ages of the sedimentary units is critical for evaluating their processes of formation and for developing an understanding of paleoceanographic and paleoclimatic variability of the region. Few dating techniques are available for many of these units, either because they are too old (for radiocarbon methods) or because the sediments themselves consist of material redeposited during debris-flow transport.

This study was undertaken to evaluate the utility of amino-acid racemization (AAR) as a tool for correlation and age estimation of carbonate layers in sediments of the Amazon Fan, sampled during Ocean Drilling Program (ODP), Leg 155. AAR has been applied to a variety of Quaternary geochronological problems (Miller and Brigham-Grette, 1989; Wehmiller, 1993). Studies of AAR in foraminiferal tests from several well-dated marine sediment cores (Wehmiller and Hare, 1971; Kvenvolden et al., 1973; King and Neville, 1977; Müller, 1984; Fletcher, 1994) have provided the background and control on the use of this method for estimation of ages in marine sediments. The AAR methods employed in this study have required the analysis of mixtures of foraminiferal tests, thereby yielding a result that represents the average age of all the samples processed. More sensitive AAR methods can be applied to higher resolution study of age mixtures within a given sedimentary unit (Stathoplos and Hare, 1988).

${ }^{1}$ Flood, R.D., Piper, D.J.W., Klaus, A., and Peterson, L.C. (Eds.), 1997. Proc. ODP, Sci. Results, 155: College Station, TX (Ocean Drilling Program)

${ }^{2}$ Dept. of Geology, University of Delaware, Newark, DE 19716, U.S.A. jwehm@udel.edu

${ }^{3}$ College of Marine Studies, University of Delaware, Newark, DE 19716, U.S.A.

\section{METHODS}

Samples were obtained from the ODP core repository (Bremen) in February 1995. Samples were selected to represent as wide an age range as possible, based primarily upon shipboard interpretations of biostratigraphic and lithostratigraphic information. The samples and their independent age estimates (in terms of marine oxygen isotope stages) are summarized in Table 1. Age estimates for several of the units have changed significantly during post-cruise interpretations, especially for those units that pre-date oxygen isotope Stage 5 (R. Flood and D. Piper, pers. comm., 1996).

All samples were wet-sieved ( 250 and $63 \mu \mathrm{m})$ after soaking overnight in distilled water to disaggregate the enclosing sediment. Gentle ultrasonic treatment was also used for disaggregation, but no chemical dispersant was used in this initial cleaning step. After sieving, samples were air-dried in sterile plastic dishes. All samples were then examined using a binocular microscope to evaluate the amount of clean, intact foraminiferal material for amino acid analysis and to remove (using sterile glass pipets) any noncarbonate material. Most of the samples did not yield sufficient carbonate material for analysis (see Table 1), and all analyzed samples were mixtures of different genera, rather than being single taxa as would be ideal. Relative foraminiferal abundances of each sample were not determined; however, taxonomic analyses reported in each site report (Flood, Piper, Klaus, et. al., 1995) are used as a basis for comparison of possible intergeneric effects on racemization rates. Larger samples will be required for any future work, especially if single genera are to be used. The kinetic implications of the mixed-taxa sampling will be discussed below.

Samples selected for analysis were transferred to pre-weighed glass screw-cap vials for weighing and final cleaning. The analyzed samples weighed between 1.0 and $3.5 \mathrm{mg}$. Cleaning was conducted according to procedures developed by Johnson (1990): samples were immersed in a 1:1 mixture of $\mathrm{H}_{2} \mathrm{O}_{2}$ and triple-distilled $\mathrm{H}_{2} \mathrm{O}$ for $30 \mathrm{~min}$ at room temperature, rinsed with triple-distilled $\mathrm{H}_{2} \mathrm{O}$, then immersed in $7 \mathrm{M} \mathrm{NH}_{4} \mathrm{OH}$ for $24 \mathrm{hr}$. These chemically cleaned samples were then rinsed (triple-distilled $\mathrm{H}_{2} \mathrm{O}$ ) to neutrality, dried in a vacuum oven $\left(50^{\circ} \mathrm{C}\right)$, and hydrolyzed in $6 \mathrm{~N} \mathrm{HCl}$ at $105^{\circ} \mathrm{C}$ for $22 \mathrm{hr}$, sealed under nitrogen.

Hydrolyzed samples were desalted by addition of HF to precipitate calcium as $\mathrm{CaF}_{2}$, which was removed by centrifugation. The su- 
Table 1. Leg 155 samples selected for amino acid racemization study.

\begin{tabular}{|c|c|c|c|c|c|c|}
\hline $\begin{array}{l}\text { Core, section, } \\
\text { interval }(\mathrm{cm})\end{array}$ & $\begin{array}{c}\text { Depth } \\
\text { (mbsf*) }\end{array}$ & $\begin{array}{c}\text { Temperature } \\
\text { gradient } \\
(\text { degrees } / \mathrm{km})\end{array}$ & $\begin{array}{l}\text { Sample } \\
\text { volume } \\
\left(\mathrm{cm}^{3}\right)\end{array}$ & Stage** & Lab no. & Notes \\
\hline $936 \mathrm{~A}-1 \mathrm{H}-1,12-17$ & & & 20 & 1 & 960001 & 3 \\
\hline $942 \mathrm{~A}-1 \mathrm{H}-1,34-40$ & & & 20 & 1 & & 1 \\
\hline $942 \mathrm{~B}-4 \mathrm{H}-1,113-115$ & & & 10 & $5 \mathrm{a}$ & & 2 \\
\hline 942B-4H-1, 132-134 & & & 10 & $5 \mathrm{a}$ & & 2 \\
\hline $942 \mathrm{C}-5 \mathrm{H}-1,61-67$ & $\sim 70$ & $\sim 38$ & 20 & $5 \mathrm{e}$ & 960039 & 3 \\
\hline 936A-44X-1, 91-93 & & & 10 & $7(9)$ & & 2 \\
\hline $936 \mathrm{~A}-44 \mathrm{X}-1,124-126$ & & & 10 & 7 (9) & & 2 \\
\hline $944 \mathrm{~A}-25 \mathrm{X}-5,96-101$ & $\sim 225$ & $\sim 24$ & 20 & $7 ?$ & $960002 \& 960041$ & 3,4 \\
\hline 944A-39X-1, 134-136 & & & 10 & $9(9 ?)$ & & 2 \\
\hline $944 \mathrm{~A}-39 \mathrm{X}-2,6-8$ & & & 10 & $9(9 ?)$ & & 2 \\
\hline $931 \mathrm{~B}-38 \mathrm{X}-4,38-40$ & & & 10 & $11(7)$ & & 2 \\
\hline $931 \mathrm{~B}-38 \mathrm{X}-4,53-55$ & $\sim 350$ & $\sim 25$ & 10 & 11(7) & 960040 & 3 \\
\hline $946 \mathrm{~A}-23 \mathrm{X}-3,119-121$ & & & 10 & 11(7) & & 2 \\
\hline $946 \mathrm{~A}-23 \mathrm{X}-4,3-5$ & & & 10 & $11(7)$ & & 2 \\
\hline
\end{tabular}

Notes: * = depth (m below seafloor) for only those Pleistocene samples actually analyzed. Temperature gradient from Leg 155 site reports: 931, p. 167; 942 , p. 566; 944, p. 627 (Flood, Piper, Klaus, et al., 1995). In notes column, $1=$ sufficient material—analyses not done because Stage 1 age duplicated by $960001 ; 2=$ insufficient foraminifer material-no analysis possible; $3=$ analysis conducted — see Table 2 ; and $4=$ coarse and fine fractions $(>250 \mu \mathrm{m}$ and $>63,<250 \mu \mathrm{m})$ analyzed. $* *=$ preliminary shipboard stage assignments; postcruise age assignments in parentheses.

pernatant (containing the total hydrolyzable amino acid mixture) was dried under a nitrogen stream and derivatized for gas chromatographic (GC) analysis using the NTFA-isopropyl method (Engel and Hare, 1985), as discussed by Wehmiller (1984a) and Miller and BrighamGrette (1989). Gas chromatographic analysis was conducted using a 50-m glass capillary column coated with Chirasil-Val installed in a Perkin-Elmer 3920 gas chromatograph. Detection was by flame ionization. These methods have all been routine in the Delaware lab for at least $15 \mathrm{yr}$ (Wehmiller, 1984a, 1984b; Wehmiller et al., 1988). High-pressure liquid chromatographic methods (HPLC) were not employed in this study because they yield data for only one amino acid, D-alloisoleucine/L-isoleucine, which is a relatively slow-racemizing amino acid. The GC method yields data for at least four amino acids, including several that are faster racemizing, and hence have greater potential for resolving small age differences (see Wehmiller, 1984a, 1984b).

\section{RESULTS}

The D/L values for four analyzed samples are given in Table 2. One sample was split into coarse $(>250 \mu \mathrm{m})$ and fine $(63-250 \mu \mathrm{m})$ fractions for analysis as described above. $\mathrm{D} / \mathrm{L}$ values for alanine, valine, leucine, aspartic acid, phenylalanine, and glutamic acid were calculated from electronic integration of peak areas or, in most cases, from measurement of peak heights by ruler and magnifying glass. Small sample sizes, combined with chromatographic "noise" and occasional interfering peaks, prevented complete analysis in some cases. D/L values for other amino acids can occasionally be obtained by the methods used here, but are limited by sample size and more frequent chromatographic interferences. Nitrogen-specific gas chromatographic detection (Wehmiller, 1984b) would probably permit more sensitive analysis and eliminate some interfering peaks, but this detection method was not available at the time of sample processing. The D/L values given in Table 2 are "best values" derived from a combination of peak-height and peak-area measurements. Their uncertainties (given in parentheses) are conservative estimates of the range of possible values for each D-L ratio. Sample sizes prevented the obtaining of more than two chromatograms of any one sample derivative. Also listed in Table 2 are those foraminiferal taxa that are identified as being "common" in the depth intervals of the analyzed samples, as obtained from specific site reports (Flood, Piper, Klaus, et. al., 1995). This information is important for qualitative evaluation of potential taxonomic effects on racemization rates.

\section{DISCUSSION}

It is important to emphasize that a number of factors combine to make the interpretation of the results in Table 2 very preliminary. The small sample size, combined with the great potential for "natural" contamination when dealing with foraminifer samples with large surface-area to mass ratios, and the ambiguities associated with analysis of mixed-genera samples, all demand that great caution be invoked in the interpretation of racemization data. Additionally, when mixtures of samples (even of the same genus) are analyzed, there is the potential for different sample ages to be combined. Differences in burial depths (Table 1) also indicate that each sample may have been exposed to effective temperature differences large enough to affect significantly the estimation of age differences between samples.

In spite of these potential problems, the results given in Table 2 appear to be in good agreement with previously published $\mathrm{D} / \mathrm{L}$ values for mixed foraminifer samples of this age. Figure 1 presents the results from Table 2 in this context.

In Figure 1, we plot data from Müller (1984) and Kvenvolden et al. (1973) for comparison with results from this study. Müller's (1984) data were for D-alloisoleucine/L-isoleucine (hereafter A/I) values on single taxa (Globorotalia and Orbulina, fast and slow-racemizing taxa, respectively) and mixed-assemblage specimens from dated eastern North Atlantic sediments. The mixed-assemblage data appear to reflect roughly equal abundances of the slow- and fast-racemizers in the core studied by Müller (1984). Kvenvolden et al. (1973) used gas chromatographic methods (similar but not identical to those used here) on mixed assemblages from Caribbean and North Atlantic cores. The "D/L value" plotted in Figure 1 is for either A/I from Müller (1984) or D/L leucine from Kvenvolden et al. (1973) or from Table 2. Prior results (Kvenvolden et al., 1973) indicate that D/ L leucine and $\mathrm{A} / \mathrm{I}$ values in foraminifers are within $5 \%$ to $10 \%$ in the $\mathrm{D} / \mathrm{L}$ range 0.0 to 0.5 ; the $\mathrm{D} / \mathrm{L}$ leucine values from Table 2 are plotted in Figure 1 with an uncertainty that is large enough to account for analytical confidence and any ambiguity in comparison between $\mathrm{D} / \mathrm{L}$ leucine and A/I values.

The $\mathrm{D} / \mathrm{L}$ leucine value of $\sim 0.15$ for the sample assigned to oxygen isotope Substage 5e (155-942C-5H-1, 61-67 cm) is similar to previously published results for either mixed or single-taxon aminostratigraphic analyses of samples of this age (Fig. 1). Although the Leg 155 Substage 5e sample is from $\sim 70$ meters below seafloor (mbsf; Table 1) rather than the shallower piston-core depths for most specimens reported in previous studies (Kvenvolden et al., 1973; Müller, 1984), the combined effect of taxonomy, bottom-water, and down- 
Table 2. Amino acid enantiomeric ratio data, Leg 155 mixed foraminifer samples.

\begin{tabular}{ccccccccc}
\hline & & \multicolumn{9}{c}{ D/L values } \\
\cline { 3 - 8 } Lab no. & Site & Alanine & Valine & Leucine & $\begin{array}{c}\text { Aspartic } \\
\text { acid }\end{array}$ & $\begin{array}{c}\text { Phenyl- } \\
\text { alanine }\end{array}$ & $\begin{array}{c}\text { Glutamic } \\
\text { acid }\end{array}$ & Notes \\
\hline 960001 & 936 & $0.10(0.03)$ & $0.02(0.01)$ & $0.02(0.01)$ & $0.12(0.03)$ & nd & nd & 1 \\
960039 & 942 & nd & nd & $0.15(0.01)$ & $0.26(0.01)$ & $0.15(0.03)$ & $0.09(0.03)$ & 1,3 \\
960002 & 944 & $0.37(0.02)$ & $0.19(0.01)$ & $0.27(0.01)$ & $0.37(0.02)$ & $0.26(0.02)$ & $0.18(0.02)$ & 1 \\
960041 & 944 & $0.32(0.04)$ & $0.17(0.03)$ & $0.16(0.02)$ & $0.25(0.02)$ & $0.22(0.02)$ & $0.15(0.02)$ & 2 \\
960040 & 931 & $0.43(0.03)$ & $0.15(0.02)$ & $0.26(0.01)$ & $0.40(0.02)$ & $0.25(0.03)$ & $0.19(0.03)$ & 1 \\
\hline
\end{tabular}

Notes: Numbers in parentheses are estimated analytical uncertainty. In Notes column, $1=>250 \mu \mathrm{m}$ sample analyzed; $2=63-250 \mu \mathrm{m}$ sample analyzed; and $3=$ small peaks and baseline drift, large uncertainties for phenylalanine and glutamic acid. nd = not determined. The following foraminiferal taxa are identified as being "common" in the Pleistocene samples analyzed: 931: Globorotalia tumida, G. trilobus, G. inflata, and Globigerinoides ruber; 942: G. truncatulinoides and Neogloboquadrina dutertrei; 944: G. tumida and Pulleniatina obliquiloculata (Flood, Piper, Klaus, et al., 1995). These results are useful in evaluating possible taxonomic effects on racemization rates (see text).

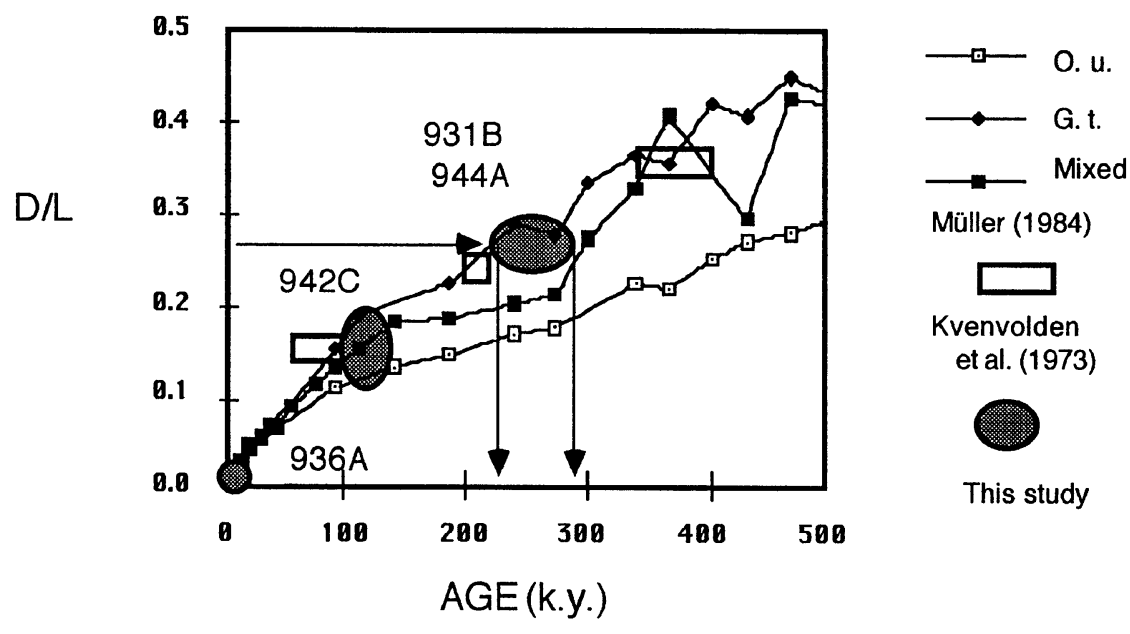

Figure 1. D-alloisoleucine/L-isoleucine values plotted vs. sample age for Orbulina universa (O.u.), Globorotalia tumida/truncatulinoides (G.t.), and mixed foraminifer specimens (all published by Müller, 1984), and D/L leucine values for mixed foraminifer samples published by Kvenvolden et al. (1973). Shaded circles are data points for D/L leucine for the four Leg 155 samples in Table 2 . D/L values for these two amino acids are within $10 \%$ of each other over the range under consideration. The G.t. and O.u. curves delineate fast- and slow-racemization kinetics, respectively. The sample from Hole $942 \mathrm{C}$ conforms well to its oxygen isotope Substage 5e age; the Hole 944A sample, interpreted in terms of fast-racemization kinetics, appears to be no younger than about 220 k.y. and no more than about $300 \mathrm{k} . \mathrm{y}$. in age, as indicated by the projection of the D/L leucine values to the time scale. The Hole 931B sample also plots at this same position, probably because of compensating geothermal and taxonomic kinetic factors.

hole temperatures has yielded $\mathrm{D} / \mathrm{L}$ results that are within a general analytical range of $\sim \pm 15 \%$ that is considered acceptable for this preliminary study.

$\mathrm{D} / \mathrm{L}$ values for the Stage 1 sample $(155-936 \mathrm{~A}-1 \mathrm{H}-1,12-17 \mathrm{~cm})$ are all much lower than those observed in the other samples reported here and are consistent with their Holocene age assignment. Other amino acids in these same Leg 155 samples also conform to the relative age sequence inferred from the leucine $\mathrm{D} / \mathrm{L}$ values.

The D/L leucine value of 0.27 for Sample 155-944A-25X-5, 96$101 \mathrm{~cm}$ (coarse fraction), with an independently estimated age greater than oxygen isotope Stage 5, falls within the range of values observed by Müller (1984) for fast-racemizing taxa with ages of 220300 k.y. Ignoring potential geothermal kinetic effects, this would be the maximum age assignment, assuming that the analyzed foraminifer assemblage from this sample is dominated by fast-racemizing taxa (a reasonable assumption, based on the published foraminifer abundances [from Flood, Piper, Klaus, et. al., 1995, as summarized in Table 2] and the studies by King [1980] and Wehmiller [1980] on the relation between foraminifer taxonomy and racemization rates). The D/L values for the fine fraction of the same sample (155-944A$25 \mathrm{X}-5,96-101 \mathrm{~cm})$ are lower than those for the coarse fraction, as would be expected if leaching or contamination had affected this fraction. Relative age estimates for the different samples should be based on the same size fractions, assuming comparable preservation and no taxonomic effects on racemization. Only after analysis was it learned that Sample 155-944A-25X-5, 96-101 cm, came from a disturbed zone, possibly incorporating samples of mixed ages (Flood, Piper, Klaus, et al., 1995, pp. 605-608). Additional analyses from adjacent depths should be conducted to evaluate the effects of this disturbance on the AAR data.

The kinetic effects of geothermal heating become significant when samples have been buried at substantially different depths or in sections with markedly different geothermal gradients (Katz et al., 1979; Bada and Man, 1980). These effects are best understood with results for an individual taxon from multiple, well-dated depths (to $>300 \mathrm{mbsf}$ ) in a single hole. Because we are comparing limited results for mixed-genera samples from different holes, it is difficult to assess the kinetic implications of the different sample burial depths reported here. Nevertheless, some limiting age intervals can be proposed for Sample 155-931B-38X-4, 53-55 cm, using the oxygen isotope Substage 5e sample $(155-942 \mathrm{C}-5 \mathrm{H}-1,61-67 \mathrm{~cm})$ as a reference sample (we do not consider disturbed Sample 155-944A-25X-5, 96$101 \mathrm{~cm}$, in this thermal modeling). Based on sample depths and geothermal gradients for these two samples (Table 1), it is estimated that Sample 155-931B-38X-4, 53-55 cm, could have "reached" (during its overall burial history) a temperature $5^{\circ}$ to $6^{\circ} \mathrm{C}$ warmer than that of 
Sample 155-942C-5H-1, 61-67 cm. The integrated kinetic effect of this time-temperature difference could have resulted in an effective temperature difference of between $3^{\circ}$ and $5^{\circ} \mathrm{C}$. This difference, combined with information on racemization temperature sensitivity (Katz et al., 1979; Bada and Man, 1980), would have raised the racemization rate constant for Sample 155-931B-38X-4, 53-55 cm, to $\sim 1.5-$ $2 \times$ that of the "calibration" Sample 155-942C-5H-1, 61-67 cm. If both of these samples had similar taxonomic mixtures, then they could be interpreted as being nearly equal in age in spite of their very different $\mathrm{D} / \mathrm{L}$ values. However, a Substage 5e age estimate for Sample $155-931 \mathrm{~B}-38 \mathrm{X}-4,53-55 \mathrm{~cm}$, is not consistent with the biostratigraphic age estimate (Table 1). This sample has a greater percentage of the slower racemizing Globigerinoides ruber (Table 2; G. ruber is recognized as a slow-racemizer by Johnson, 1990), and is the most deeply buried of the samples analyzed here (Table 1). If the Stage 5 and 7 age assignments for Samples 155-942C-5H-1, 61-67 cm, and 155-931B-38X-4, 53-55 cm, are correct, then it appears that the taxonomic and geothermal effects on racemization rates in these two samples have counteracted each other, resulting in the older sample yielding $\mathrm{D} / \mathrm{L}$ values that are consistent with its Stage 7 age assignment.

\section{CONCLUSIONS}

Amino acid analysis of foraminifer tests extracted from sediment plugs from Leg 155 cores appears to be a viable method for estimating the relative ages of samples. The present study was hampered by smaller-than-expected foraminifer abundances in the available sediment samples. In spite of this limitation, results consistent with previous work have been obtained on two Leg 155 samples whose ages (oxygen isotope Stage 1 and Substage 5e) were known from independent information. Two other samples, one from a disturbed section of Hole 944A, contain foraminifer tests that are estimated to be $\sim 250$ k.y. in age, based on simplifying assumptions about geothermal and taxonomic kinetic factors. Further work will require that larger numbers of foraminifer tests be extracted from selected samples and that more sensitive analytical methods be employed so that mixed-assemblage data can be compared with results for single taxa. Before racemization methods can be confidently applied to inter-hole correlation, geothermal kinetic effects must be fully evaluated by analysis of multiple samples from a single downhole section.

\section{REFERENCES}

Bada, J.L., and Man, E.H., 1980. Amino acid diagenesis in Deep Sea Drilling Project cores: kinetics and mechanisms of some reactions and their applications in geochronology and in paleotemperature and heat flow determinations. Earth-Sci. Rev., 16:21-55.

Engel, M.H., and Hare, P.E., 1985. Gas liquid chromatographic separation of amino acids and their derivatives. In Garrett, G.C. (Ed.), Chemistry and Biochemistry of Amino Acids: London (Chapman and Hall), 462-479.
Fletcher, R.R., 1994. Comparative planktonic foraminiferal biostratigraphy of the Colombia Basin and Northeast Gulf of Mexico [Ph.D. dissert.]. Univ. of Delaware, Newark.

Flood, R.D., Piper, D.J.W., Klaus, A., et al., 1995. Proc. ODP, Init. Repts., 155: College Station, TX (Ocean Drilling Program).

Johnson, B.J., 1990. The Pleistocene planktonic foraminiferal aminostratigraphy of Ocean Drilling Program Hole 625B in the Northeast Gulf of Mexico. [M.S. thesis]. Univ. of Delaware, Newark.

Katz, B.J., Harrison, C.G.A., and Man, E.H., 1979. The effects of the geothermal gradient on amino acid racemization. Earth Planet. Sci. Lett., 44:279-286.

King, K., Jr., 1980. Applications of amino acid biogeochemistry for marine sediments. In Hare, P.E., Hoering, T.C., and King, K., Jr. (Eds.), Biogeochemistry of Amino Acids: New York (John Wiley), 377-392.

King, K., Jr., and Neville, C., 1977. Isoleucine epimerization for dating marine sediments: importance of analyzing monospecific foraminiferal samples. Science, 195:1333-1335.

Kvenvolden, K.A., Peterson, E., Wehmiller, J.F., and Hare, P.E., 1973. Racemization of amino acids in marine sediments determined by gas chromatography. Geochim. Cosmochim. Acta, 37:2215-2225.

Miller, G.H., and Brigham-Grette, J., 1989. Amino acid geochronology: resolution and precision in carbonate fossils. Quat. Int., 1:111-128.

Müller, P.J., 1984. Isoleucine epimerization in Quaternary planktonic foraminifera: effects of diagenetic hydrolysis and leaching, and AtlanticPacific intercore correlations. Meteor Forschungsergeb. C., 38:25-47.

Stathoplos, L., and Hare, P.E., 1988. Amino acid analysis of individual fossil planktonic foraminiferal tests. Yearbook-Carnegie Inst. Wash., 87:127132.

Wehmiller, J.F., 1980. Intergeneric differences in apparent racemization kinetics in molluscs and foraminifera: implications for models of diagenetic racemization. In Hare, P.E., Hoering, T.C., and King, K., Jr. (Eds.), Biogeochemistry of Amino Acids: New York (John Wiley), 341-355.

, 1984a. Interlaboratory comparison of amino acid enantiomeric ratios in fossil mollusks. Quat. Res., 22:109-120.

1984b. Relative and absolute dating of Quaternary mollusks with amino acid racemization: evaluation, application, questions. In Mahaney, W.C. (Ed.). Quaternary Dating Methods: Amsterdam (Elsevier), 171193.

, 1993. Applications of organic geochemistry for Quaternary research: aminostratigraphy and aminochronology. In Engel, M.H., and Macko, S.A. (Eds.), Organic Geochemistry: New York (Plenum), 755783.

Wehmiller, J.F., and Hare, P.E., 1971. Racemization of amino acids in marine sediments. Science, 173:907-911.

Wehmiller, J.F., Belknap, D.F., Boutin, B.S., Mirecki, J.E., Rahaim, S.D., and York, L.L., 1988. A review of the aminostratigraphy of Quaternary mollusks from United States Atlantic Coastal Plain sites. In Easterbrook, D.L. (Ed.), Dating Quaternary Sediments. Spec. Pap.-Geol. Soc. Am., 227:69-110.

Date of initial receipt: 5 February 1996

Date of acceptance: 9 May 1996

Ms 155SR-217 